\title{
MIND MAPPING DALAM PERKULIAHAN PENGANTAR PENDIDIKAN
}

\author{
Loesita Sari $^{1}$, Melisa Wahyu Fandyansari ${ }^{2}$, Prismadio Sandiansyah P.M. ${ }^{3}$ \\ ${ }^{1}$ Pendidikan Ekonomi, IKIP Budi Utomo \\ e-mail: loesitasari@budiutomomalang.ac.id \\ 2Pendidikan Ekonomi, IKIP Budi Utomo \\ e-mail: melisawahyufandyansari@budiutomomalang.ac.id \\ ${ }^{3}$ Pendidikan Ekonomi, IKIP Budi Utomo \\ e-mail: prismadhios511@gmail.com
}

\begin{abstract}
The study was conducted using the Dick and Carey research and development model method with nine steps of implementation. The study involved 90 first semester students of Class 2019. The test activities carried out were the pretest and posttest tests. The handout was tested by three validators namely material experts, media experts and linguists. And the handout design was tested again on students, namely the small-scale test and the large-scale test. The final results of this study, obtained the results that the hand out of educational subjects in the form of Mind Mapping included in good and decent criteria
\end{abstract}

Keywords: Mind Mapping, Introduction to Education

\begin{abstract}
Abstrak
Penelitian dilakukan menggunakan metode research and development model Dick and Carey dengan sembilan langkah pelaksanaannya. Penelitian melibatkan 90 mahasiswa semester satu Angkatan 2019. Kegiatan uji yang dilaksanakan adalah uji pretest dan uji posttest. Handout diuji oleh tiga validator yaitu ahli materi, ahli media serta ahli bahasa. Dan rancangan handout dilakukan uji kembali pada mahasiswa yaitu uji berskala kecil dan uji skala besar. Hasil akhir dari penelitian ini, diperoleh hasil bahwa hand out matakuliah pengantar pendidikan berbentuk Mind Mapping masuk dalam kriteria baik dan layak.
\end{abstract}

Kata kunci : Mind Mapping, Pengantar Pendidikan 


\section{A. PENDAHULUAN}

Indonesia merupakan negara kepulauan yang terdiri dari ribuan pulau dari Sabang sampai Merauke, dimana masing-masing daerah memiliki karakteristik adat dan budaya yang beragam pula. Bahasa, makanan, tarian, pakaian adat, norma atau hukum adat, serta berbagai macam keanekaragaman budaya dari masingmasing daerah menjadi ciri khasnya. Namun meskipun beragam dan berbeda, tetaplah menjadi sebuah kesatuan yaitu NKRI atau Negara Kesatuan Republik Indonesia. Seluruh daerah disatukan dengan satu bahasa yang sama yaitu bahasa Indonesia, disamakan dengan satu bendera yaitu bendera merah putih dan lain sebagainnya. Dan satu lagi kesamaan yang sama dari seluruh nusantara adalah pendidikannya. Pendidikan di Indonesia terdiri dari beberapa tingkatan, yaitu: Pendidikan usia dini atau prasekolah, Taman Kanak-kanak (TK), Sedolah Dasar (SD), Sekolah Menengah Pertama (SMP), Sekolah Menengah Atas (SMA), dan Perguruan Tinggi. Pada tingkatan SD hingga SMA, kurikulum ditentukan secara nasional yang menjadi rujukan bagi seluruh sekolah. Dan perkembangan kurikulum sekolah di Indonesia adalah:

1. Kurikulum 1947 atau disebut dengan Rentjana Pelajaran 1947. Merupakan kurikulum pertama yang ada setelah Indonesia merdeka. Kurikulum ini dirubah menjadi sarat akan jiwa dan rasa nasionalisme dan dipenuhi dengan pendidikan Pancasila.

2. Kurikulum 1952 dikenal dengan Rentjana Pelajaran Terurai 1952. Kurikulum ini penyempurnaan dari kurikulum sebelumnya, yang arahnya sudah pada sistem Pendidikan Indonesia.

3. Kurikulum 1964 yairu Rentjana Pendidikan 1964. Kurikulum ini memiliki ciri Pancawardhana, yaitu pengembangan moral, memiliki kecerdasan, penguasaan emosional, keprigelan (keterampilan softskill), dan keterampilan jasmani. 
4. Kurikulum 1968. Tujuan dari kurikulu ini untuk membentuk manusia Pancasila yang sejati, kuat, sehat jasmani dan rohani, baik akhlak, moral dan budi pekertinya, serta berkeyakinan agama.

5. Kurikulum 1975. Kurikulum ini dilandasi oleh pengaruh MBO atau manajement by objective. Metode, materi dan tujuan pengajaran dirinci dalam PPSI atau Prosedur Pengembangan Sistem Instruksional.

6. Kurikulum 1984. Pada kurikulum ini, siswa dijadikan sebagai subjek belajar dengan tugas mengamati, mengelompokkan, mendiskusikan, dan melaporkan. Atau juga disebut CBSA (cara belajar siswa aktif).

7. Kurikulum 1994 dan Suplemen 1999.

8. Kurikulum 2004 yang dikenal dengan KBK atau Kurikulum Berbasis Kompetensi. Kurikulum KBK bercirikan: ketercapaian kompetensi siswa, berorientasi pada hasil belajar dan keberagaman.

9. Kurikulum 2006 yaitu KTSP (Kurikulum Tingkat Satuan Pendidikan). Pusat kurikulum mengacu pada jiwa desentralisasi sistem Pendidikan Indonesia, dan terakhir

10. Kurikulum 2013. Merupakan kurikulum yang memiliki tiga aspek penilaian yaitu aspek pengetahuan, aspek keterampilan dan aspek perilaku.

Dari perkembangan kurikulum di atas dapat juga diperhatikan bahwa beberapa kurikulum memperhatikan aspek perkembangan teknologi untuk dasar perubahannya, dengan tujuan siswa atau peserta didik dapat mengikuti perkembangan jaman dan tidak ketinggalan informasi atau menjadi gagap teknologi. Tidak hanya kuriuklum saja, perkembangan teknologi yang saat ini terjadi, utamanya di Indonesia sangatlah pesat. Hampir semua usia dan semua golongan masyarakat telah mengikuti perkembangan teknologi dan menikmati serta mengaplikasikannya dalam berbagai kegiatan sehari-hari, baik untuk kegiatan produktif maupun hanya untuk bersenang-senang semata. Di semua lini sudah terhubung dengan kecanggihan teknologi yang sekarang bagaikan candu bagi masyarakat Indonesia. Termasuk juga dalam dunia Pendidikan. Pelajar atau 
mahasiswa tidak perlu lagi membawa tas yang berat karena isinya beberapa buku yang tebal, menggunakan kertas dalam kegiatannya, atau menggunakan pena atau tinta untuk kegiatan mencatat materi, tapi siswa cukup membawa sebuah gadget yang terhubung dengan internet. Dan dari gadget inilah semua informasi dan berbagai keperluan dalam proses pembelajaran dapat dipenuhi. Siswa dapat membuka atau membaca buku secara online tanpa dibatasi ruang, siswa juga dapat mengetahui berbagai perkembangan informasi di seluruh dunia dari internet. Namun tidak selalu sisi positif yang ada pada internet yang mampu membantu kegiatan seorang siswa. Bagi sebagian siswa atau mahasiswa yang kurang dapat menjaga diri atau menahan keinginan diri, perkembangan teknologi justru dijadikan sebagai alat untuk berbuat yang kurang baik yang dapat merugikan diri sendirinya maupun semua orang yang ada di sekitarnya.

Perkembangan teknologi secara positif juga dirasakan pada Pendidikan yaitu buku atau acuan dalam pembelajaran. Salah satunya yaitu hand out perkuliahan bagi mahasiswa. Hand out adalah bahan ajar yang disusun secara sistematis, terstruktur yang digunakan oleh peserta didik guna memudahkan proses pemahaman terhadap suatu materi. Menurut Sukiman (2011) hand out adalah "bagian dari kesatuan belajar yang terencana dan dirancang guna membantu siswa secara individual untuk memahami materi dan mencapai tujuan belajar". Nasution (dalam silabus.web.id, 2020) "hand out dirumuskan sebagai unit yang lengkap dan terdiri atas sebuah rangkaian kegiatan yang disusun dengan tujuan membantu siswa mencapai sejumlah tujuan yang telah dirumuskan secara khusus dan jelas". Pada pelaksanaannya, hand out yang akan dikembangkan harus memperhatikan lima karakteristik hand out, yaitu:

1. Self Instruction. Penggunaan hand out dapat dilakukan secara mandiri oleh peserta didik dengan memuat: tujuan pembelajaran yang jelas, materi dibahas secara rinci, contoh ilustrasi yang dapat mendukung pemahaman materi, adanya soal-soal latihan, menggunakan bahasa yang mudah 
dipamahami atau komunikatif, dan ada kesimpulan di setiap akhir pembahasan.

2. Self Contained. Semua materi dibahas dalam satu hand out, sehingga siswa dapat mempelajari semua materi hingga selesai.

3. Stand Alone. Materi yang disampaikan tidak terpecah ke bahan ajar lain.

4. Adaptif. Buku ajar atau hand out dapat disesuaikan dengan perkembangan teknologi.

5. User Friendly. Hand out yang disusun mudah dipamami oleh penggunanya.

Dalam penelitian ini, hand out yang disusun berbentuk Mind Mapping dan merupakan bagian dari perkuliahan Pengantar Pendidikan. Pada Program Studi Pendidikan Ekonomi IKIP Budi Utomo, matakuliah Pengantar Pendidikan disajikan pada semester satu (I) sebagai matakuliah dasar kependidikan. Matakuliah ini menjadi dasar sebelum mahasiswa mendapatkan matakuliah kependidikan lainnya. Dengan harapan mahasiswa setelah mendapatkan matakuliah pengantar Pendidikan dapat dengan mudah memahami matakuliah kependidikan lain. Matakuliah ini memiliki kode INS201 dengan bobot 3 SKS. Beberapa materi yang menjadi pembahasan pada hand out matakuliah yang disajikan dalam model Mind Mapping antara lain:

1. Hakekat manusia

2. Hakekat pendidikan

3. Dimensi kemanusiaan dan Pendidikan

4. Aliran-aliran pendidikan

5. Unsur-unsur pendidikan

6. Permasalahan pendidikan di Indonesia, dan

7. Sistem pendidikan nasional

Dalam perkuliahan, hand out berbentuk Mind Mapping digunakan sebagai cara untuk membantu mahasiswa memperlajari materi pengantar pendidikan secara mudah. Hand out disusun secara elektronik dengan tujuan agar semakin mudah mahasiswa mengakses materi serta bisa dibaca dimana saja dan kapan saja. Hal ini 
sejalan dengan amanah yang tertuang dalam Permendikbud Nomor 3 Tahun 2020 tentang Standar Nasional Pendidikan Tinggi, dimana melalui peraturaan ini, dalam perkuliahan mahasiswa harus menjadi pusat, bukan lagi sekedar penerima informasi.

Mind Mapping dipilih sebagai salah satu cara memudahkan mahasiswa menerima atau memahami materi perkuliahan. Secara teori, Mind Mapping dapat diartikan sebagai "proses memetakan pikiran untuk menghubungkan konsepkonsep permasalahan tertentu dari beberapa cabang sel saraf yang membentuk korelasi konsep menuju sebuah pemahaman yang dapat dituangkan dalam sebuah kertas dengan diberikan hiasan ilustrasi agar mudah dimengerti oleh si pembuat". Dala website tigaserangkai.com, Mind Mapping dipopulerkan oleh seorang penulis dan bintang televisi yang berasal dari Inggris. Buzan (2008) menyebutkan bahwa Mind Mapping adalah "alat berpikir organisasional dan juga cara termudah untuk menempatkan informasi dalam otak dan nantinya mengambil informasi saat dibutuhkan". Mind Mapping memiliki manfaat, antara lain adalah:

1. Meningkatkan kemampuan otak untuk mengingat sesuatu secara utuh dan lebih detail

2. Dapat meningkatkan kemampuan untuk memanajemen informasi, berkonsentrasi, daya imajinasi dan memori

3. Menjadikan kegiatan belajar lebih menyenangkan dan lebih efisien atau hemat waktu

4. Materi yang awalnya sulit, dapat lebih mudah dipahami, dimengerti dan dikuasai dengan Mind Mapping.

(tigaserangkai.com)

Dengan Mind Mapping, diharapkan mahasiswa tidak lagi mengalami kesulitaan untuk memahami materi, dan dapat dengan mudah menguasai, memahami dan mengerti materi perkuliahan, utamanya matakuliah pengantar pendidikan. Di bawah ini merupakan salah satu desain mind mapping hand out perkuliahan Pengantar Pendidikan. 


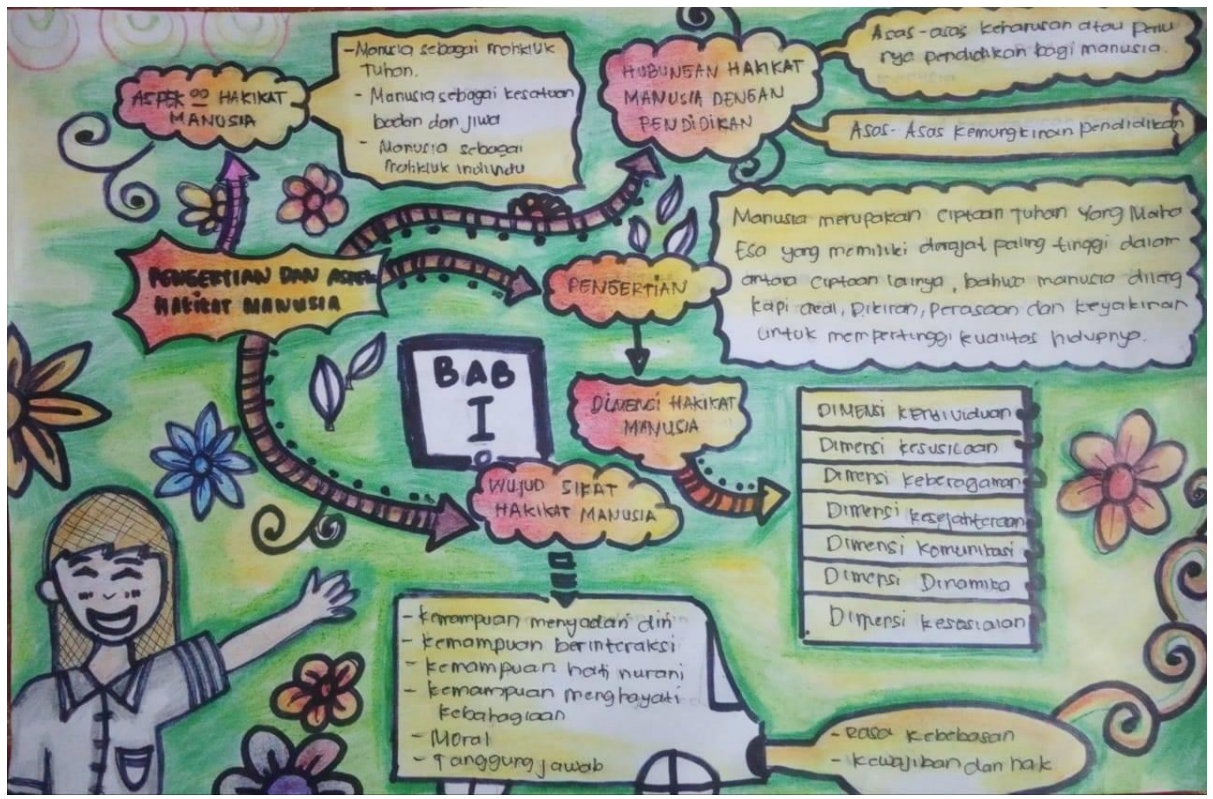

Gambar 1.

Desain Mind Mapping

\section{B. METODE PENELITIAN}

Penelitian dengan judul Mind Mapping Dalam Perkuliahan Pengantar Pendidikan ini dilaksanakan pada mahasiswa baru Program Studi Pendidikan Ekonomi IKIP Budi Utomo, atau pada mahasiswa Angkatan 2019. Penelitian dilaksanakan sejak bulan November 2019 hingga Januari 2020. Penelitian menggunakan metode penelitian yaitu research and development atau $R n D$.. Amile and Renesnes menjelaskan bahwa penelitian pengembangan adalah "suatu proses pengembangan perangkat pendidikan yang telah dilakukan melalui serangkaian riset dan mnggunakan berbagai metode dalam sebuah tahapan”. Sedangkan Seels and Richey (1994) berpendapat bahwa " $R n D$ adalah suatu kajian sistematik terhadap desain, pengembangan dan evaluasi program, proses dan produk pembelajaran yang memenuhi kriteria validitas, praktis serta efektif". Menurut Borg and Gall (1983) RnD adalah "research and development is a powerful strategy for improving practice. It is a process used to develop and validate educational products", atau diterjemahkan menjadi "penelitian pengembangan merupakan strategi yang kuat untuk meningkatkan praktek. Dan merupakan proses yang 
digunakan untuk mengembangkan dan menilai produk pendidikan". Produk pendidikan yang dimaksud di atas haruslah mengandung empat (4) unsur, antara lain:

1. Produk tidak hanya perangkat keras seperti hand out, buku ajar, video atau film, tetapi juga perangkat lunak seperti kurikulum, model pembelajaran, prosedur pembelajaran, dan lain-lain

2. Produk yang dikembangkan merupakan produk baru dan/ atau memodifikasi produk yang sudah ada

3. Produk yang dikembangkan benar-benar memiliki manfaat bagi dunia pendidikan

4. Produk yang telah dikembangkan dapat dipertanggungjawabkan secara praktis maupun keilmuan.

Pelaksanaan penelitian ini memiliki beberapa tahapan, yaitu untuk menentukan:

1. desain produk yang akan dikembangkan (desain hipotik)

2. serta mendeskripsikan tugas-tugas berbagai pihak yang terlibat dalam penelitian

3. kebutuhan sarana dan prasarana yang akan digunakan selama penelitian

4. tahap-tahap saat pelaksanaan uji lapangan

5. Pelaksanaan penelitian ini menggunakan model instruksional Dick and Carey.

Pada model instruksional Dick and Carey terdapat 10 tahapan, namun karena keterbatasan, penelitian ini hanya menggunakan 9 tahapan saja, seperti pada gambar di bawah ini: 


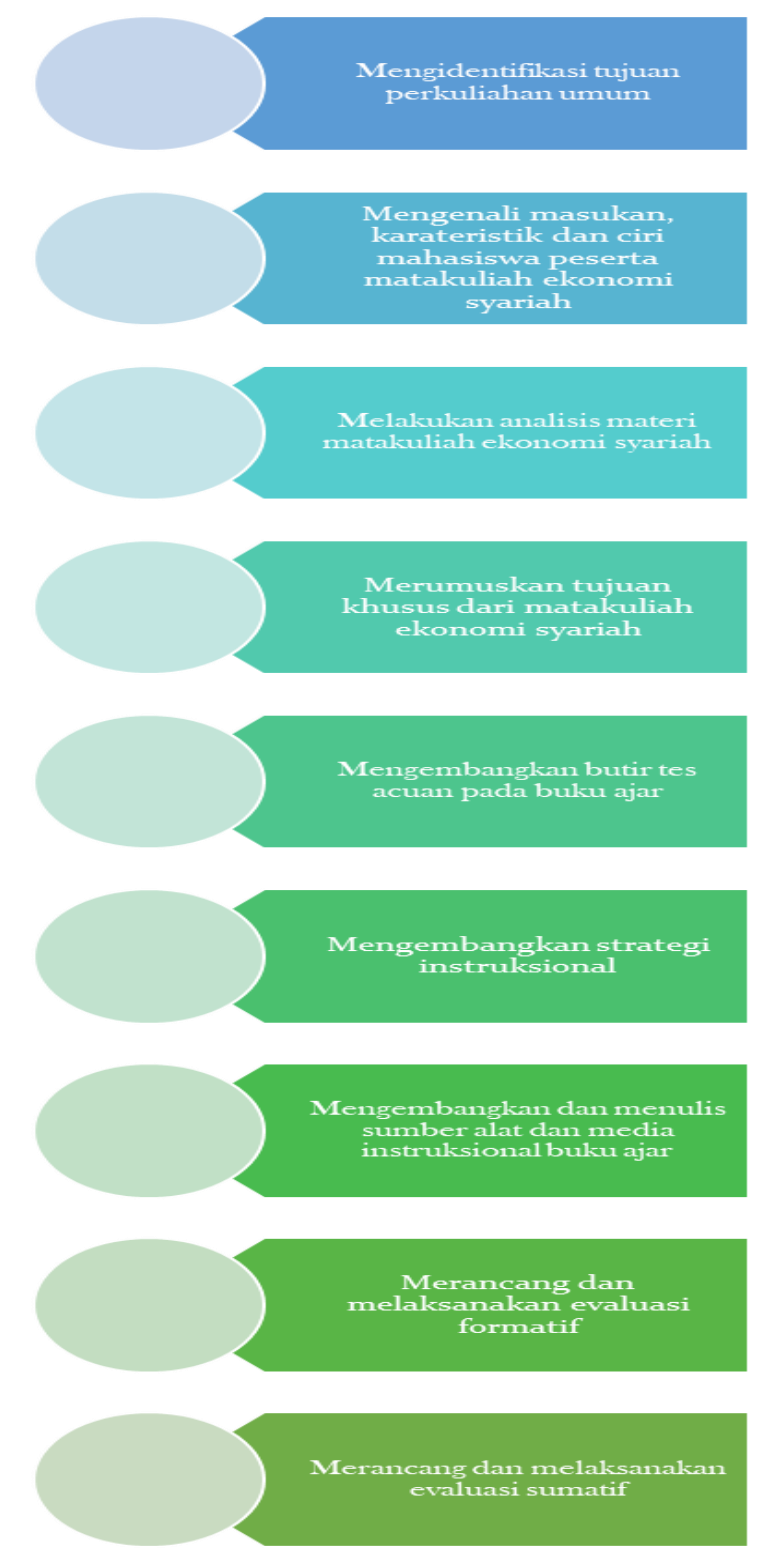

Gambar 2.

Tahapan penelitian model instruksional Dick and Carey

Seperti yang telah disebutkan di awal, penelitian dilaksanakan pada mahasiswa baru Angkatan 2019 Prodi Pendidikan Ekonomi kelas A dan B yang berjumlah total 90 mahasiswa. Pengumpulan data menggunakan instrumen angket. Selain digunakan untuk pengumpulan data dari mahasiswa, angket juga digunakan untuk memperoleh data dari ahli serta dari hasil uji. Penelitian ini 
menyertakan tiga ahli atau validator, yang terdiri dari ahli media, ahli bahasa, dan ahli materi. Pelaksanaan uji dilakukan dalam uji skala kecil dan uji skala besar.

\section{HASIL DAN PEMBAHASAN}

Sembilan langkah yang menjadi tahapan dalam pelaksanaan penelitian ini adalah: 1) Mengidentifikasi tujuan perkuliahan umum, 2) Mengenali masukan, karateristik serta ciri mahasiswa peserta matakuliah pengantar pendidikan, 3) Melakukan analisis materi-materi yang dibahas pada hand out matakuliah pengantar pendidikan, 4) Merumuskan tujuan khusus hand out MK pengantar pendidikan, 5) Mengembangkan butir tes acuan pada hand out, 6) Mengembangkan strategi instruksional, 7) Mengembangkan dan menulis sumber, alat dan media instruksional hand out Mind Mapping, 8) Merancang dan melaksanakan evaluasi formatif, 9) Merancang dan melaksanakan evaluasi sumatif.

Setelah Sembilan langkah tadi terlaksana, berikutnya adalah melakukan kegiatan pretest dan posttest guna mengetahui peningkatan hasil perkuliahan pengantar pendidikan. Hasil pretest didapat 73,7\% dan hasil uji posttest didapat hasil rata-rata 84,9\%. Sehingga secara keseluruhan dapat disimpulkan bahwa hand out berbentuk Mind Mapping yang dikembangkan ini termasuk dalam kategori layak digunakan.

Sedangkan untuk hasil dari validator, yaitu: 1) ahli materi pendidikan didapat nilai sebesar 82,1\%, 2) dari ahli media didapat hasil uji sebesar 89,2\%, dan 3) dari ahli bahasa memberikan hasil uji sebesar 88,5\%. Kegiatan uji tidak hanya dilakukan pada para validator saja, tapi juga dilakukan pada mahasiswa. Uji yang dilakukan adalah uji skala kecil dan uji skala besar. Uji skala kecil dilakukan dengan melibatkan 50 mahasiswa angkatan 2019 yang merupakan peserta perkuliahan pengantar pendidikan. Sedangkan uji skala besar melibatkan semua mahasiswa peserta perkuliahan pengantar pendidikan sejumlah 90 mahasiswa. Uji skala kecil dilakukan dengan menerapkan dan menguji materi Bab 1 dan mendapat 
respon dari mahasiswa yaitu kualifikasi baik atau setara dengan tingkat prosentase $83,2 \%$ dan uji skala besar mendapat hasil baik atau sama dengan tingkat prosentase $89,6 \%$.

\section{KESIMPULAN}

Penelitian ini merupakan penelitian research and development, pada pelaksanaannya, kegiatan uji yang dilaksanakan adalah uji pretest serta kegiatan uji posttest. Juga uji dari ahli materi, ahli media serta ahli bahasa. Dan terakhir uji dilakukan kembali pada mahasiswa yaitu uji materi berskala kecil dan uji penggunaan hand out dengan skala peserta besar. Dari hasil uji pretest dan posttest, validasi pada beberapa ahli dan uji skala kecil serta skala besar, diperoleh hasil bahwa hand out matakuliah pengantar pendidikan berbentuk Mind Mapping masuk dalam kriteria baik dan layak.

\section{DAFTAR RUJUKAN}

Ali, Mohammad \& ASrori, Muhammad. 2014. Metodologi dan Aplikasi Riset Pendidikan. Jakarta: PT Bumi Aksara

Arifin, Zainul. 2012. Model Penelitian dan Pengembangan. Bandung: PT Remaja Rosdakarya

Arikunto, Suharsimi. 2006. Prosedur Penelitian Suatu Pendekatan Praktik. Jakarta: PT Rineka Cipta

Borg and Gall. 1983. Educational Research An Introduction. New York: Longman Inc.

Dick, W. \& Carey, L. 1996. The Systematic Design of Instruction. New York: Harper Collin Publishers

Ghufron, Anik. 2011. Pendekatan Penelitian dan Pengembangan (R\&D) di Bidang Pendidikan dan Pembelajaran. UNY

Semiawan, Conny R. 2007. Catatan Kecil Tentang Penelitian dan Pengembangan Ilmu Pengetahuan. Jakarta: Prenada Media Group 
http://ejurnal.budiutomomalang.ac.id/index.php/ecoducation

Winarsunu, Tulus. 2006. Statistic Dalam Penelitian Psikologi dan Pendidikan. Malang: UMM Press

www.tigaserangkai.com

Pengertian Hand out Pembelajaran.https://www.silabus.web.id/pengertian-hand out-pembelajaran/ 